\title{
Enhancing Design Education Using Mid-Program Strategies in Electronic Systems Engineering
}

\author{
Doug Wagner, Dave Duguid, and Paul Laforge \\ Electronic Systems Engineering, Faculty of Engineering and Applied Science, University of Regina \\ Douglas.Wagner@uregina.ca, Dave.Duguid@uregina.ca, Paul.Laforge@uregina.ca
}

\begin{abstract}
The Electronic Systems Engineering program at the University of Regina has incorporated design content into its fifth semester to improve the design experience of the students. A problem was identified where the quality of final year design projects was lacking. It was proposed that adding design content into the fifth semester could bridge the gap in design content between the first and upper years.

$A$ concerted effort between the course and lab instructors of several courses within the ESE curriculum has been made to address this problem. In particular, the fifth semester analog circuits course was restructured as an analog design course where students are required to design circuits on assignments, in the lab, and on exams.

The addition of this design content in the fifth semester of the program has improved the quality of the capstone and senior design courses and projects.
\end{abstract}

Keywords: accreditation, analog circuits, curriculum development, design, graduate attributes.

\section{INTRODUCTION}

The Electronic Systems Engineering (ESE) program is one of five Canadian Engineering Accreditation Board (CEAB) accredited programs offered through the University of Regina. The program highlights a "systems engineering" approach to education, and broadly fits within the electronics and computer engineering classification of programs accredited in Canada. The ESE program prides itself on extensive "hands on" education, something that is particularly well suited to the electronics field, with extensive laboratory educational experience.

Within the systems engineering envelope, design skills are a key educational attribute identified within the ESE program. Design is one of twelve graduate attributes identified by Engineers Canada in their Outcomes Based Assessment criteria [1], however design exercises represent a vehicle for delivering many of the other graduate attributes mandated by Engineers Canada.

The ESE team has addressed a challenge that we had experienced in the delivery of design content, through the structuring of fifth semester engineering courses, to bridge the gap we had existed between introductory design focused courses, and senior and capstone design courses in our program.

Through the ESE fifth semester Analog Circuits, class (now Analog Design) a structured approach to analyzing and solving real world problems is presented to the students. This approach entails the teaching of a series of specific components, and circuits, similar to conventional analog circuit course content. In concert with the devices, and the associated circuits, a series of real world scenarios are presented in course assignments, laboratories and examinations. This approach challenges the students to apply and synthesize their knowledge of these circuits to provide practical and diverse solutions to problems. All design problems allow for multiple approaches, and design strategies, however students are critically evaluated in terms of their adherence to the performance and operating specifications of the devices they use in their solutions.

The challenges of this approach have necessitated an annual "course tuning" to ensure students are challenged, but not overloaded in their fifth semester. The emphasis on current electronic components and design strategies also necessitates an emphasis on manufacturer's design literature, in place of more traditional texts.

Teaching design can be challenging; ESE's experience has been that as more design tasks are incorporated into the course, the challenges in managing both instructor and student workload increase. These challenges have resulted in an evolutionary approach to structuring the ESE curriculum in Regina.

The change in design content for the analog design course from 2003 to 2011 is presented in section two, and in section three the scope of the analog design course is outlined. An example of the design lab content is presented in section four. In section five, the challenges of implementing such a course are discussed, examples of the type of design problems to be solved in an exam setting are presented, and the benefits of implementing design in this course are listed. Finally, conclusions are made in section six.

\section{INITIAL ESE CURRICULUM}


2003 marked the first iteration of design content modifications in design course content. Prior to this time, design was presented in the first year of the engineering program, through an engineering design and communications course, with a heavy focus on engineering sciences in years two and three. Heavy design course content was then seen in the remaining two years of the program. A graph of the relative design content of the ESE curriculum by year for 2003 is shown in Fig. 1.

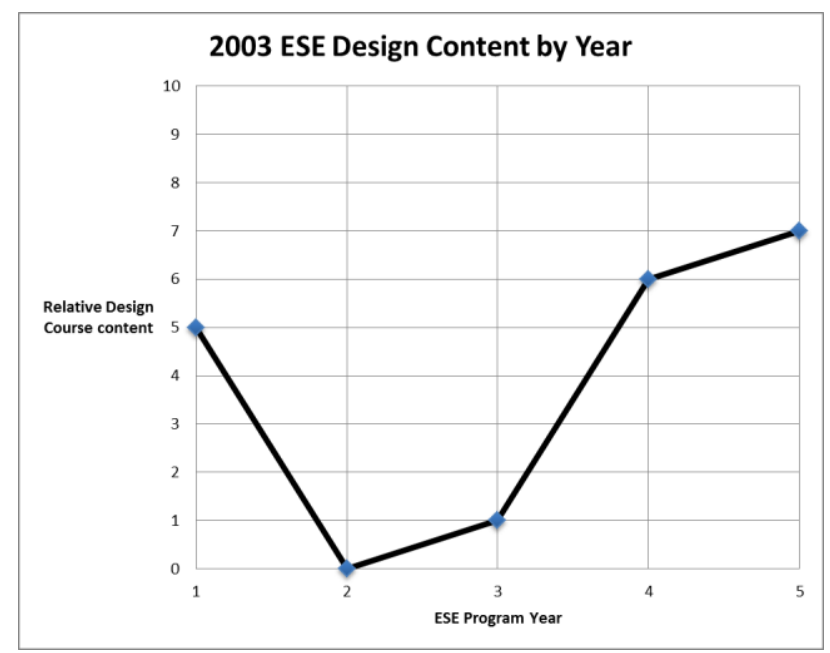

Fig. 1. Relative design content in the ESE curriculum by year in 2003 .

The gap in design experience created an issue in the ESE program. In year four, the students were faced with their first major design challenges in conceiving and implementing a microprocessor based design project. The students faced issues in coming to grips with a number of hardware, assembly, testing and troubleshooting skills. The resulting overload in student workload led to poorer project execution and a less than optimal learning experience for many of the students.

The solution implemented in the Electronic Systems Engineering program was to increase the design content significantly in two courses in the ESE fifth semester. One course, ENEL 384, dealing with combinational and discretely clocked logic, incorporated a combined labproject platform that allowed the students to implement an open ended design project at the end of their class. The other class that implemented design concepts was the ENEL 283, Analog Electronics class, which evolved to Analog Design. The result has been a shift in both the quantity, as shown in Fig. 2, and quality of design experience in the ESE program.

The resulting increase in year three design content has dramatically improved the design accomplishments of students in the fourth and fifth years of the ESE program, and has facilitated the addition of further design content in fifth year ESE courses.

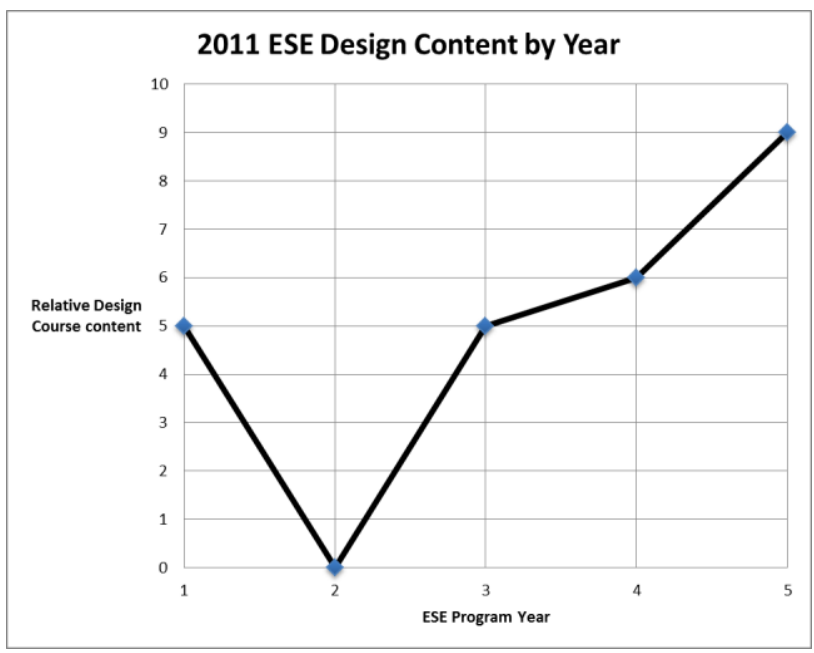

Fig. 2. Relative design content in the ESE curriculum by year in 2011 .

\section{DESIGN IN ANALOG ELECTRONICS}

ENEL 283 was originally tasked with delivering engineering content on the operation and configuration of various operational amplifier circuits, and discrete transistor configurations. The course was modeled on one of the many texts [2] which exist for this course material, and followed the text format quite closely. The course now includes the course material dealing with op amp circuits, with a heavy emphasis on application to design problems, power supply regulation, and analog timer devices. Discrete transistors are confined to switching and voltage follower applications.

The design experience entered the course in two areas, the first being the incorporation of a design project requiring the construction of unique circuit solution to one of a number of given problems, the second coming through examples, and examination questions focused on design problems.

\section{ENEL 283 LAB EXPERIENCE}

The lab and lecture components of the Analog Design course are tightly coordinated to reinforce, and augment the design experience students receive. The traditional laboratory experience can be highly procedural. In ENEL 283 there is a conscious effort to bring the students into a mode where they are given a task and required to develop their own procedural approach based on the information available through the various device data sheets. The lab process includes in lab design exercises that reflect a common approach with course assignment and examination questions. An example of such a lab in the 
Analog Design course is shown in Fig. 3. The final design project comprises $50 \%$ of the overall lab mark, and is jointly evaluated by the lab and course instructors.

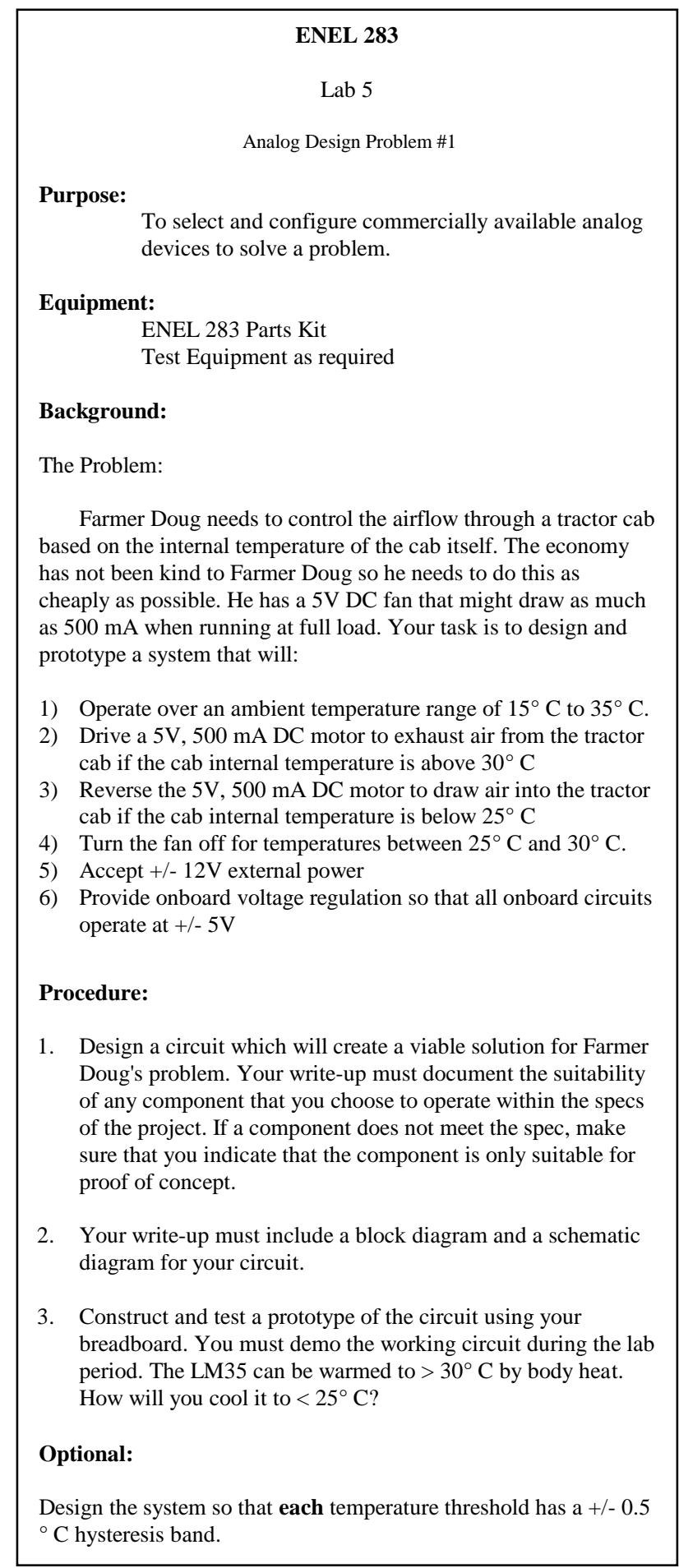

Fig. 3. Example of design in the lab for the Analog Design course.

\section{CHALLENGES AND OUTCOMES IN IMPLEMENTING DESIGN IN ANALOG ELECTRONICS}

The incorporation of design into ENEL 283 was not a seamless process. The initial incorporation of the lab project employed the approach used in later ESE design classes, where the students were allowed to choose any project which interested them using analog design concepts. The faculty members found the lack of structure led the students to build projects, but unfortunately, they were often not linked to the class concepts and skills targeted in the curriculum. It seemed Google was seen as a better resource that the lab and course instructors. To mitigate this problem, a more structured design problem was given as students then had to work with one of four defined problems. The design problems are also coordinated with a parts kit that the students are required to purchase for the lab and design exercises. The early experience with design projects led to a recognition of a balance issue represented in Fig. 4.

\section{Balance of Design versus Knowledge}

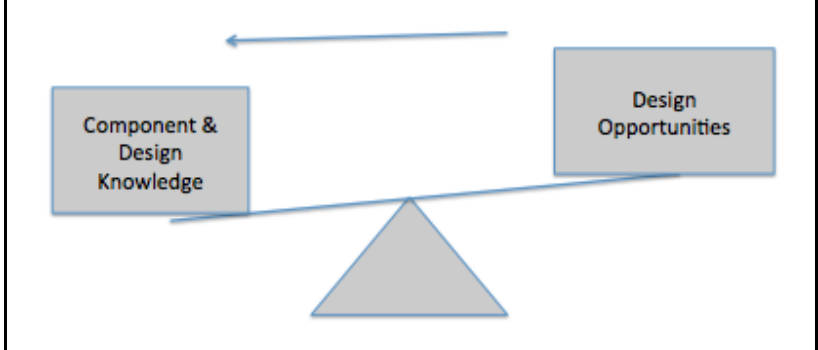

Fig. 4. Balance of design versus knowledge when teaching courses.

The approach to course material delivery necessitated acknowledging this balance, and making conscious efforts to ensure design emphasis did not detract from the engineering science component of the course.

While there is a prescribed text for this course, ESE has found that one of the key learning resources available for students is found through manufacturers' data sheets. One of the key design skill outcomes sought in ENEL 283 is developing an understanding of interpreting manufacturers' absolute ratings, electrical specifications, and application notes, and being able to separate technical information pertinent to design from marketing information.

The synthesis of a design problem from a stated problem has proven to be one of the larger challenges in teaching design in the fifth semester of the engineering program. Engineering design is stressed through a series of examination problems, which force the student to distill 
a described problem into a design with the latitude for design choices.

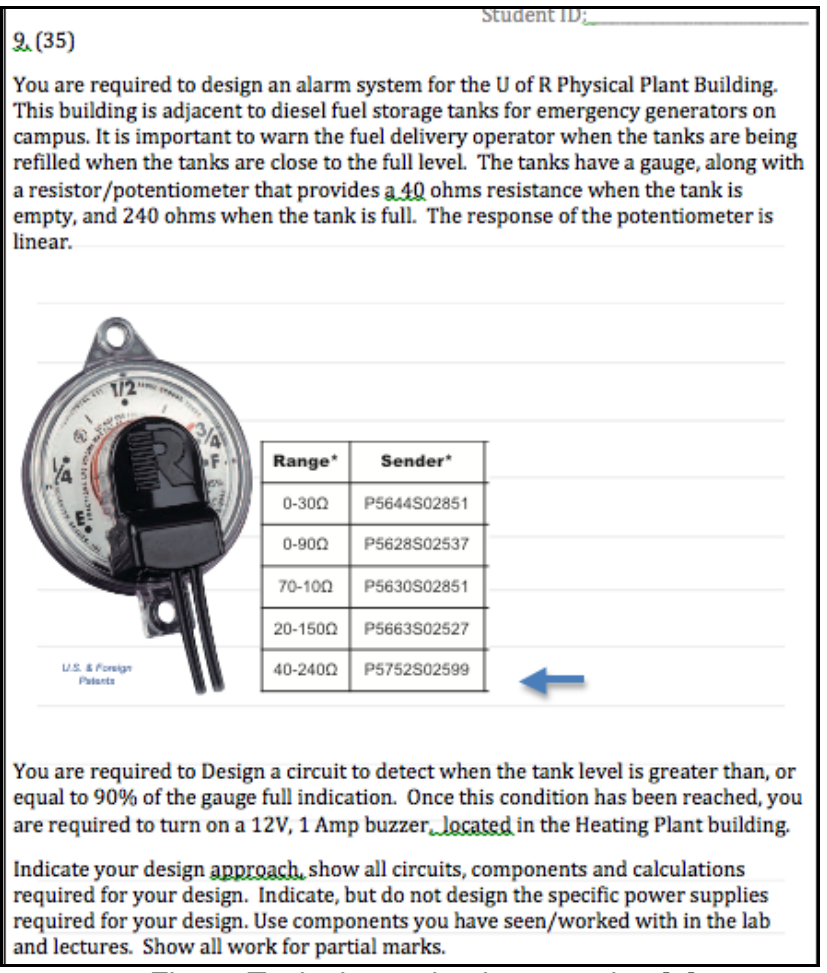

Fig. 5. Typical examination question [3].

Examination questions such as the one shown in Fig. 5 present challenges for some students, particularly those who do not count English as their first language, however by the end of the course, most students have an enhanced ability to identify design problems from within a generally stated problem.

As a result of the changes, and ongoing refinements that have been made in the ENEL 283 Analog Electronics course, the ESE program has observed the following outcomes:

- Students have an increased ability to evaluate and select electronic, and electro-mechanical devices based on industry standard data sheets and marketing information.

- Students are able to translate a general problem into a design specification that guides their implementation of a design solution.

- Students have increased confidence when they tackle more complex design problems involving both analog and digital/microprocessor based design exercises in more senior classes.

- Students develop an increased appreciation for timelines in prototype design and evaluation, and the reality of troubleshooting in design implementation.

- The addition of design content has not adversely affected the overall curriculum content in ENEL 283, arguably, the design content has improved the overall retention of concepts through design application.

The increased emphasis on electronic system design has been a positive change in the ESE curriculum. One reason for this change's success has been the ability of the respective fifth semester faculty to work in an integrated manner to monitor, and if necessary adjust student workload (through changes in due dates as an example) to ensure the increased demands of design projects do not adversely impact a student's educational experience.

\section{Conclusion}

The addition of design course content into the third year, fifth semester of the Electronic Systems Engineering program at the University of Regina has been a positive change in the program's continuing goal of delivering a quality systems engineering program to its students. The implementation of mid-program design has allowed for an improvement in later course accomplishments by ESE's students.

The path to design implementation requires ongoing re-evaluation of the objectives, and potential drawbacks that can occur with the addition of open-ended course deliverables. The evaluation process has already led to a number of course content and structure changes over the eight year period the design component has been implemented.

Student workload management has become a significant factor that requires management and monitoring on the part of faculty and is a key element in ensuring that the design content does in fact achieve the desired academic outcome.

It is also important to acknowledge that the evaluation of the increased design work on the part of the students increases the faculty workload significantly; since there are many right answers, there has to be a significant investment in student evaluation. ESE at the University of Regina is fortunate to have a strong culture and history of cooperation between a number of faculty instructing both in the labs and lectures. Without this high level of cooperation it would be difficult to see the achievements that have been realized in the Electronic Systems Engineering program.

\section{References}

[1] Engineers Canada, "Canadian Engineering Accreditation Board: Accreditation Criteria and Procedures”, pp. 12-13, 2011. Available as of May 16, 2012 from http://www.engineerscanada.ca/files/w_Accreditation_Criter ia_Procedures_2011.pdf 
Proc. 2012 Canadian Engineering Education Association (CEEA12) Conf.

[2] Mark H. Horenstein, Microelectronic Circuits and Devices. Prentice Hall, 1995 (2nd ed.), 1126 pp. \{ISBN:

$9780137013357\}$
[3] Rochester Gauges Inc. http://www.rochestergauges.com, Accessed: May 16, 2012.

CEEA12; Paper 029

Winnipeg, MB; June 17-20, 2012

-5 of $5-$ 